\title{
Effect of oral contraceptives on visual evoked potentials in premenopausal females
}

\author{
Rajpoot RS ${ }^{* 1}$, Tandon $S .{ }^{2}$, Pradeep Kumar ${ }^{3}$, Verma ${ }^{4}$ \\ ${ }^{1}$ Dr Raveendra singh Rajpoot, Associate Professor, Department of Physiology, UPRIMS \& R, Saifai, Etawah, UP, India, \\ ${ }^{2}$ Dr Stuti Tandon, II year Junior Resident, Department of Anatomy, KGMU, Lucknow, UP, India, ${ }^{3}$ Dr Pradeep Kumar, \\ Professor, Department of Physiology, KGMU, Lucknow, UP, India, ${ }^{4}$ Dr Dileep Verma, Associate Professor, Department \\ of Physiology, KGMU, Lucknow, UP, India.
}

Corresponding Author: Dr Raveendra singh Rajpoot, Email: drrsrajpoot@yahoo.com

\begin{abstract}
Introduction: The sex hormones are not only restricted to the influence the reproductive organs and processes in the female body, but also have great effect on the functioning of the nervous system. Evoked potentials are one of the many electrophysiological parameters, used to assess the neuronal functioning. The aim of this prospective study was to analyze the effects of oral contraceptive pills on the visual evoked potentials in premenopausal females. Methods: The VEP was measured in 76 females during follicular and luteal phases of their menstrual cycle, and latencies of the three waveforms N70, P100 and N135 were measured. All the subjects were prescribed oral contraceptive pills containing 0.03 $\mathrm{mg}$ estradiol and 0.15 levonorgestrel. The VEP latencies were measured again after 4 months of oral contraceptive intake. Result: The result showed an increase in all the three latencies of VEP waveforms due to oral contraceptive intake. Although the increase in latencies were not significant $(P>0.05)$. Conclusion: Hence it was concluded that VEP seems to be influenced by the female steroid hormones during the menstrual cycle and also due to oral intake in the form of contraceptives.
\end{abstract}

Key words: Visual Evoked Potential, Visual Evoked Response, Menstrual Cycle, Oral Contraceptives.

\section{Introduction}

The influence of female sex hormones is not restricted to endocrine control of reproductive functions, but it extends to many regions of the central nervous system. Different sex hormones are known to exert their influences of the central nervous system in different ways. They are said to affect sexual differentiation of the brain, pattern and organization of neural circuits in different parts of the brain [1]. Cyclic production of female sex hormones in females has been linked to hyperkinetic movement disorders [2], odor detection thresholds [3-5], taste threshold [6] mood [7], activity of neurotransmitters [8], and also to convulsability [910]. Estrogen along with other steroid hormones may have direct effects upon visual and auditory system and the pathways involved, they also indirectly influence the central processing and the blood flow through respected parts of the brain [11]. Being an anabolic

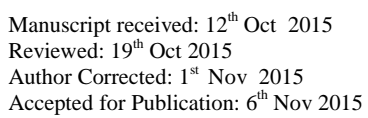

hormone decrease in estrogen is associated with decrease in metabolic rates [12] and thereby could influence the activity of neurotransmitters and the conduction time in the neural pathways [13-14]. Estrogen has been shown to modify the activity of GABA (Gama-aminobutyric acid) receptor leading to delayed synaptic conduction time [15].

Recent development in electrophysiological measurement techniques have made possible the recording of minute electrical activities arising from within the nervous system. Since the discovery of brain stem evoked potentials in 1970s [16-17], curiosity has continuously escalated, both in the audiological and visual neurological fields [18].

The Visual Evoked Potential (VEP) is a gross electrical response, which reflects the processing of visual message from the macular area of retina to the primary visual area 17, 18 and 19 of occipital cortex. It is 
recorded by placing electrodes on the scalp at specific places. VEPs may be recorded by using either flash stimuli or pattern reversal stimuli (checks or stripes). The pattern reversal response is more sensitive to relatively small changes in visual acuity level as compared to the flash response as well as it is considered better in detecting defects and diseases of the optic pathway. Hence, the pattern reversal visual evoked potentials are more useful than the flash evoked potentials [19]. A normal VEP consists of a series of waveforms of opposite polarity. The negative waves are denoted as $\mathrm{N}$ and the positive ones as $\mathrm{P}$. The time taken by any particular wave to appear is known as latency of that wave. Most commonly studied waveforms are N70, P100 and N135 [20]. Visual evoked potentials may be affected by many variables as age, sex, visual acuity and pupillary size etc. It has also shown to vary with the technique used in recording it for example size of checks, illumination and field size [21]. The gender differences in the evoked potentials can also be due to head size, skin thickness [22] or metabolic differences [23] apart from the effect of hormones [24].

Ovulatory women have significant cyclic fluctuation in their hormonal status during menstrual cycle. One more situation in which the female hormonal status varies is use of oral contraceptive pills. There are approximately 400 million oral contraceptive pill users worldwide, most of them are in 19 - 30 year age group [25]. There are many studies which were designed to study the effect of oral contraceptive pill use on auditory brain stem evoked potentials [15, 25-26] but very less work has been done in relation to the VEPs.

\section{Aims and Objectives}

A prospective study has been designed to see the effect of oral contraceptive use on Visual Evoked Potentials with respect to different phases of the menstrual cycle.

\section{Materials and Methods}

The study was performed in the department of Obstetrics and Gynecology, KGMU, Lucknow, UP, India. The study was approved by the institutional ethical committee. All the participants gave their written consent to participate in the study. It was a prospective study with the objective to monitor the modifications in VEP during oral contraception. A total of 76 volunteers (mean age $25 \pm 4.9$ years) attending the family planning OPD were registered in the study. The inclusion criteria also included a normal gynecological exam and normal duration of menstrual cycles $(28.7 \pm 4.2$ days $)$. None of the participants had a history of oral contraceptive intake or of hormonal treatment of any type. Every participant was screened thoroughly to rule out any visual disturbance, and any physical or mental illness which could affect the test for example demyelinating diseases, optic or retinopathy. Any history of medication with drugs such as antidepressants, sedatives and antipsychotics was also excluded.

Table-1: Clinical Characteristics of the Subjects

\begin{tabular}{|l|l|l|}
\hline Number of Subjects $(\mathbf{n})$ & 76 & SD \\
\hline Variables & Mean & \pm 4.9 \\
\hline Mean Age & 25 years & \pm 5.21 \\
\hline Body Weight & 52.35 kilograms & \pm 1.4 \\
\hline BMI $\left(\right.$ Kg/m $\left.\mathbf{m}^{2}\right)$ & 23.2 & \pm 4.2 \\
\hline Menstrual cycle duration & 28.7 & $\mathbf{2}$ \\
\hline
\end{tabular}

The Visual Evoked Potentials were measured by NEUROPACK FOUR Model MEM- 4104K manufactured by Nihon Kohden Corporation. The subject was explained about the test to ensure full cooperation. Subjects were instructed to avoid use of hair spray or oil. The test was done in a dimly illuminated room with the subject seated in upright posture. The standard disc electrodes were placed after preparing the skin by abrading and degreasing. The recording electrode was placed at the occiput by using conducting jelly or electrode paste as per 10-20 international system of electrode placement [27]. The scalp reference electrode is placed $12 \mathrm{~cm}$ above the nasion, ear reference was also used as noncephalic reference. The grounding electrode was placed at vertex, with impedance below 5 Kohms. 200 epochs were averaged to ensure a clear potential recording. Potentials were recorded for both the eyes as they are considered to be separate anatomically and capable of giving different waveforms in the same individual. During the menstrual cycle each subject underwent testing twice, first during follicular phase (5-8 day), and during luteal phase (18-23 day).

After taking a baseline recording of the VEPs of all the subjects they were prescribed with oral contraceptive pills 
containing 0.03 milli gram ethinyl estradiol and 0.15 milli gram levonorgestrel. The second phase of VEP recording was performed during $4^{\text {th }}$ month of oral contraceptive use. Each pill user was tested again twice in a cycle, at $7^{\text {th }}$ and $21^{\text {st }}$ days of pill intake.

\section{Results}

The visual evoked potentials were recorded from both the eyes of the subjects. The two eye wave latency averages were then used for statistical analysis.

Table-2: latencies of N70, P100 and N135 waves of VEP during Follicular and luteal phases before and after Oral Contraceptive Pill use.

\begin{tabular}{|c|c|c|c|c|c|}
\hline$\frac{\mathbf{N}}{7}$ & \multicolumn{2}{|l|}{ Mean N70 latency (ms) } & \multicolumn{2}{|l|}{ SD } & \multirow[t]{2}{*}{ P value } \\
\hline 76 & Follicular Phase (before) & Follicular phase (after & Follicular Phase (before) & $\begin{array}{l}\text { Follicular phase } \\
\text { (after) }\end{array}$ & \\
\hline & 78.62 & 79.30 & \pm 4.52 & \pm 4.69 & 0.09 \\
\hline & Luteal Phase (before) & Luteal Phase (after) & Luteal Phase (before) & Luteal Phase (after) & P Value \\
\hline & 78.63 & 79.26 & \pm 4.7 & \pm 4.64 & 0.07 \\
\hline & \multicolumn{2}{|l|}{ Mean P 100 latency (ms) } & \multicolumn{2}{|l|}{ SD } & P value \\
\hline \multirow[t]{5}{*}{76} & Follicular Phase (before) & Follicular phase (after & Follicular Phase (before) & $\begin{array}{l}\text { Follicular phase } \\
\text { (after) }\end{array}$ & \\
\hline & 116.82 & 117.64 & \pm 3.0183 & \pm 2.75 & 0.08 \\
\hline & Luteal Phase (before) & Luteal Phase (after) & Luteal Phase (before) & Luteal Phase (after) & P value \\
\hline & 113.45 & 113.88 & \pm 2.13 & \pm 2.11 & 0.07 \\
\hline & \multicolumn{2}{|l|}{ Mean N 135 latency (ms) } & \multicolumn{2}{|l|}{ SD } & Pvalue \\
\hline \multirow[t]{4}{*}{76} & Follicular Phase (before) & Follicular phase (after & Follicular Phase (before) & $\begin{array}{l}\text { Follicular phase } \\
\text { (after) }\end{array}$ & \\
\hline & 154.60 & 155.23 & \pm 4.55 & \pm 4.27 & 0.07 \\
\hline & Luteal Phase (before) & Luteal Phase (after) & Luteal Phase (before) & Luteal Phase (after) & P value \\
\hline & 157.31 & 157.81 & \pm 4.06 & \pm 3.86 & 0.051 \\
\hline
\end{tabular}

The latencies of the three important waveforms of the VEP N70, P100 and N135 have showed an increase in both the phases of menstrual cycle after the use of oral contraceptives, although the differences are not statistically significant.

\section{Discussion}

Our findings provide additional proof of the effect of ovarian sex hormones on the cognitive performance by modulating the neuronal circuits involved in visual pathways. There are no sufficient data available demonstrating the effect of contraceptive steroids on the latencies of VEP waveforms. A study with a very similar design than that of ours was done by comparing the auditory evoked potentials in women with and without oral contraceptive pills; it was revealed that the latency of potentials is more in pill users, although the differences were not statistically significant [28]. This is a similar finding as ours. A similar study designed to see the effect of oral contraceptive pills on Auditory Evoked Potentials and otoacoustic emissions (OAEs) showed a masculinizing effect on women taking contraceptive pills. This effect is contrary to the fact that both testosterone and estradiol levels are lower in pill taking women than in normally menstruating women [29].In a study Auditory Brain Stem Evoked Response was measured in postmenopausal women treated with hormone replacement therapy, it was seen that estrogen is responsible for decrease and progesterone is responsible for increase in the latencies of the waveforms [30]. One such study suggests that the temperature changes during the menstrual cycle might be responsible for the differences recorded in the VEP [28]. Some have suggested that the changes in sodium and potassium could be responsible for the changes in the conduction speed in the neural pathways or transmission speed at the synaptic junctions [12]. Estrogen has also been shown to influence the availability of acetylcholine at the synaptic terminals, which is used in many neuronal pathways [29]. The results of our study coincides with those of many other 
workers, who have found no statistically significant changes in the latencies of the evoked potential in the different phase of menstrual cycle [3,30-31].

During the menstrual cycle the androgen levels also undergo cyclical fluctuation, free testosterone showing a peak in the middle of the cycle [32]. It could be a probable candidate involved in affecting the latencies of the evoked potentials. Studies have shown substantially low levels of free testosterone levels in the oral contraceptive pill users [33]. In pill users sex steroid binding globulin production in increased, which binds testosterone and its free levels decrease [34]. Progesterone metabolites are shown to have affinity for the GABA-A receptors, they modify the affinity of the receptor to GABA. The receptor increases the chloride conductance in the neuronal membrane thus hyperpolarising it. Estrogen is said to have opposite effects on neuronal excitability [35]. Estradiol has also shown to increase the activity of N-methyl-D-aspartate (NMDA) receptors thus increasing the activity of an excitatory neurotransmitter glutamate [36].

Our study has proved the existence of changes in the latencies of the VEP waveforms with the use of oral contraceptive pills in relation to the menstrual cycle phases. Further studies with wider subject base and more detailed measurements are required to uncover the true players responsible for such variations.

\section{Funding: Nil,Conflict of interest: None. Permission of IRB: Yes}

\section{References}

1. Becker D, Creutzfeldt OD, Schwibbe M, Wuttke W. Electrophysiological and psychological changes induced by steroid hormones in men and women. Acta Phychiatrica Belga.1980;80:674-97.

2. Maggi A, Perez J. Minireview: Role of female gonadal hormones in the CNS: Clinical and experimental aspects. Life Science. 1985;37:893-06.

3. Parlee MB. Menstrual rhythms in sensory processes: a review of fluctuations in vision, olfaction, audition, taste and touch. Psychol. Bull. 1983 May;93(3),539-48.

4. Caruso S, Grillo C, Agnello C, Maioloino L, Intelisano $G$ and Serra A. A prospective study evidencing rhinomanometric and olfactometric outcomes in women taking oral contraceptives. Hum.
Reprod. 2001;16:2288-94.

5. Grillo C, La Mantia I, Triolo C, Scollo A, La Boria A, Intelisano $\mathrm{G}$ and Caruso $\mathrm{S}$. Rhinomanometric and olfactometric variations throughout the menstrual cycle. Ann. Otol. Rhinol. Larygol. 2001;110:785-89.

6. Finger TE and Silver WL. Neurobiology of Taste and Smell. Krieger Publishing Company, Malabar, Florida. 1991.

7. Bancroft J, Cook A, Williamson L. Food craving, mood and the menstrual cycle. Psychological Medicine. 1988; 18:855-860.

8. Klaiber EL, Kobayashi Y, Broverman DM. Plasma monoaminoxidase activity in regular menstruating women and in amenorrheic women receiving cyclic treatment with estrogen and progestin. Journal of Clinical Endocrinology and Catabolism. 1971;33:63038 .

9. Backstrom T. Epoleptic seizures in women related to plasma estrogen and progesterone during menstrual cycle. Acta Neurologica Scandinavica.1976;54:321-47.

10. Logothetis J, Harner R. Electrocortical activation by estrogen. Arch Neurol. 1960 Sep;3:290-7.

11. Coleman JR, Campbell D, Cooper WA, Welsh MG, and Moyer J. Auditory brainstem responses after ovariectomy and estrogen replacement in rat. Hear. Res. 1994 Nov;80(2):209-15.

12. Bruce $\mathrm{J}$ and Russel GFM. Premenstrual tension: a study of weight changes and balances of sodium, water and potassium. Lancet. 1962 Aug;2(7250):267-71.

13. Haggard $\mathbf{M}$ and Gaston GB. Changes in auditory perception in the menstrual cycle. Br. J. Audiol. 1978 Nov;12(4):105-18.

14. McEwen BS. Non-genomic and genomic effects of steroid on neuronal activity. Trends Pharm. Sci. 1991 Apr;12(4):141-7.

15. Elkind- Hirsch KE, Wallace E, Stach BA and Jerger JF. Cyclic steroid replacement alters auditory brainstem response in young women with premature ovarian failure. Hear. Res. 1992 Dec;64(1):93-98.

16. Jewett DL and Williston JS. Auditory evoked fields 
averaged from the scalp of human brain. 1971;94(4):681-96.doi: 10.1093/brain/94.4.681.

17. Sohmer H and Feinmesser M. Electrocochleography in clinical-audiological diagnosis. Arch. Otorhinolaryngol. 1974;206(2):91-102.

18. Nuwer MR. Fundamentals of evoked potentials and common clinical applications today. Electroenceph. Clin. Neurophysiol. 1998 Feb;106(2):142-48.

19. Odom JV, Bach M, Barber C, Brigell M, Marmor MF, Tormene AP, et al. Visual evoked potentials standard. Doc Ophthalmol. 2004 Mar;108(2):115-23.

20. Mishra UK, Kalita J. In; Clinical Neurophysiology. Editors, Mishra UK, Kalita J; $1^{\text {st }}$ ed. New Delhi: Elsevier; 2004. Visual Evoked Potential; pp.249-66.

21. Stockard JJ, Hughes JF, Sharbrough F. Visual evoked potentials in electronic pattern reversal: Latency variations with gender, age, and technical factors. American Journal of EEG Technology.1979;19:171204.

22. Trune DN, Miehell C and Phillips DS. The relative importance of head size, gender and age on auditory brainstem response. Hear. Res. 1988 FebMar;32(2):165-74.

23. Baker MA, and Weiler EM. Sex of listener and hormonal correlated of auditory thresholds. Br. J. Audiol. 1977 Aug;11(3):65-8.

24. McFadden D. Sex difference in the auditory system. Dev. Neuropsychol. 1998;14(2-3):261-98. Doi 10.1080/87565649809540712.

25. Caruso S, Maiolino L, Ruggolo S, Intelisano G, Farina M, Cocuzza S, Serra A. Auditory brainstem response in premenopausal women taking oral contraceptives. Hum. Reprod. 2003 Jan;18(1):85-9.

26. Swanson SJ and Dengerink HA. Changes in puretone thresholds and temporary thresholds shifts as a function of menstrual cycle and oral contraceptives. J. Speech Hear. Res. 1988 Dec;31(4):569-74.

27. American Clinical Neurophysiology Society. Guideline 5: guidelines for standard electrode position nomenclature. J Clin Neurophysiol. 2006 Apr;23(2):107-10.
28. Elkind-Hirsch KE, Stoner WR, Stach BA, Jerger JF. Estrogen influences auditory brainstem responses during the normal menstrual cycle. Hear Res. 1992 Jul;60(2):143-8.

28. Fagan PA and Church GT. Effect of the menstrual cycle on the auditory brainstem response. Audiology. 1986;25(6):321-8.

29. McFadden D. Masculinizing effects on otoacoustic emissions and auditory evoked potentials in women using oral contraceptives. Hear Res. 2000 Apr; 142(12):23-33.

30. Caruso S, Cianci A, Grasso D, Agnello C, Galvaani F, Maiolino L, Serra A. Auditory brainstem response in postmenopausal women treated with hormone replacement therapy: a pilot study $\square \square \square$ enopause. 2000 May-Jun;7(3):178-83.

31. Picton TW, Stapells DR and Campbell KB. Auditory evoked potentials from the human cochlea and brainstem. J Otolarygol. Suppl.. 1981 Aug;9:1-41.

32. Elkind-Hirsch KE, Stoner WR, Stach BA, and Jerger JJ. Estrogen influences auditory brainstem response during the normal menstrual cycle. Hear. Res. 1992 Jul;60(2):143-8.

33. Elkind-Hirsch KE, Wallace E, Malinak LR and Jerger JJ. Sex hormones regulate ABR latency, Otolaryngol. Head. Neck. Surg. 1994 Jan;110(1):46-52.

34. Morris NM, Udry JR, Khan-Dawood F and Dawood MY. Marital sex frequency and midcycle female testosterone. Arch. Sex. Behav. 1987 Feb;16(1):27-37.

35. Bancroft J, Sherwin BB, Alexander GM et al. Oral contraceptives, androgens, and the sexuality of young women:II. The role of androgens. Arch. Sex. Behav. 1991 Apr;20(2):121-35.

36. DeCherney AH. Hormone receptors and sexuality in the human female. J. Women Health Gend. Based Med. 2000;9:9-13.

37. Woolley CS, Weiland NG, McEwen BS, et al. Estradiol increases the sensitivity of hippocampal CA1 pyramidal cells to NMDA receptor-mediated synaptic input: correlation with dendritic spine density. J Neurosci 1997 Mar 1;17(5):1848-59. 
38. Weiland NG. Estradiol selectively regulates agonist binding sites on the $\mathrm{N}$-methyl-D-aspartate receptor complex in the CA1 region of the hippocampus. Endocrinology. 1992 Aug;131(2):662-8.

\section{How to cite this article?}

Rajpoot RS, Tandon S, Pradeep Kumar, Verma D. Effect of oral contraceptives on visual evoked potentials in premenopausal females. Int J Med Res Rev 2015;3(10):1151-1156. doi: 10.17511/ijmrr.2015.i10.208. 